\title{
Methods for assessing the effectiveness of energy-saving projects in construction and public utilities sector
}

\author{
Olga Kutsygina ${ }^{1, *}$, Oleg Shalnev ${ }^{1}$, and Tatiana Smotrova ${ }^{1}$ \\ ${ }^{1}$ Voronezh State Technical University, 14, Moscow avenue, Voronezh, 394026, Russia
}

\begin{abstract}
The purpose of this paper is to assess the effectiveness of investment projects in terms of ensuring energy security and sustainable economic development of construction enterprises and public utilities sector. The study revealed that existing methods for assessing the efficiency of energy-saving projects in public utilities sector are often local in nature and do not contribute to energy security. A methodology is needed for the economic feasibility of energy demand at affordable prices in the domestic and foreign markets. As a result, the authors proposed a method for solving the problem of rational use of fuel and energy resources in a system of three sectors: capital construction, public utilities sector, and the fuel and energy industry as interrelated sectors of the economy and the economic turnover of fuel and energy resources.
\end{abstract}

\section{Introduction}

Ensuring energy security of the country's economy is defined as the main goal of implementing the "Energy Strategy of Russia for the period until 2035". The energy security policy is aimed at providing economically sound internal and external demand for high-quality energy carriers at affordable prices, efficient use of energy resources, preventing inefficient expenses for energy supply to the domestic market and the scarcity of fuel and energy balances among economic entities and at federal, industrial, regional, and municipal levels. The development of energy efficient technologies in the use of energy resources by housing and utility services was defined in as first-priority technologies designed to ensure the independence and sustainability of the development of heat power industry as the basis for economic growth [1].

The problems of energy efficiency are widely represented in the papers of domestic and foreign specialists. To ensure the country's energy security, a methodology for predicting energy consumption in the domestic and foreign markets is proposed, taking into account demand, supply and environmental conditions. Also, the authors propose the economic justification for choosing the power of heat generation sources as a strategic direction to improve energy efficiency in housing and utility services [2].

\footnotetext{
* Corresponding author: olga.kutsigina@rambler.ru
} 


\section{Materials and Methods}

Energy industry of Russia faces a complex set of internal problems and extraordinary external challenges. Among the main internal problems and limitations of development, it is necessary to emphasize the technological lag of the Russian fuel and energy complex (FEC) from the level of economically developed countries and the high level of dependence on imports of certain types of equipment, materials and services, which, under sanctions, may delay the implementation of certain investment projects $[3,4,5]$. The decomposition of the investment project system is shown in the scheme (Fig. 1) in the form of a hierarchical structure of a tree-like type. In terms of objectives and goals, investment projects are divided into three classes: megaprojects, multiprojects, monoprojects.

Types of investment facilities in the economic turnover of fuel and energy resources (FER) projects are located on a separate hierarchical level in the structure of capital construction and represent a system whose elements are:

- facilities for extraction, processing and delivery of fuel resources to intermediate and final consumers;

- facilities for the production and transportation of FER to end users;

- facilities - final consumers of FER [6].

Each element of this system can have alternative options in accordance with modern trends and the development of innovations that ensure the generation of cost indicators, FER consumption and other characteristics and parameters that determine the projected value of capital investments and annual operating costs. Feedback and control in the system for managing the production and consumption of FER by buildings is manifested in the form of fees at tariffs and prices for their use. The price of FER consumed in the building operation process is determined by the conditions of functioning of enterprises of different ownership forms, which combine FEC and the system of housing and utility services [7].

In accordance with the transport task of linear programming, the goal of fuel producers that have the main funds for the extraction, processing and delivery of fuel resources is to maximize the income generation and in general form can be represented by the target function of the form

$$
F=\sum_{i=1}^{I} \sum_{j=1}^{J} \sum_{z=1}^{Z} \sum_{h=1}^{H} C_{i j z h} X_{i j z h} \rightarrow \max
$$

where $i$ - number of FER producers;

$j$ - number of FER consumers;

$z$ - type of FER;

$h$ - belonging of consumers to the market: $h=1$, if the consumer is in the country; $h=2-$ if the consumer is a foreign partner.

The amount of income is determined by the sale price $(\mathrm{C})$ of the fuel volume $(\mathrm{X})$ of the type $z$ of the producer $i$ to the consumer $j$. As the prices for FER for domestic use are lower than similar export prices, all consumers are divided into internal $(\mathrm{h}=1)$ and external $(\mathrm{h}=$ 2). The following condition is met

$$
C_{i j z 1}<C_{i j z 2 .}
$$




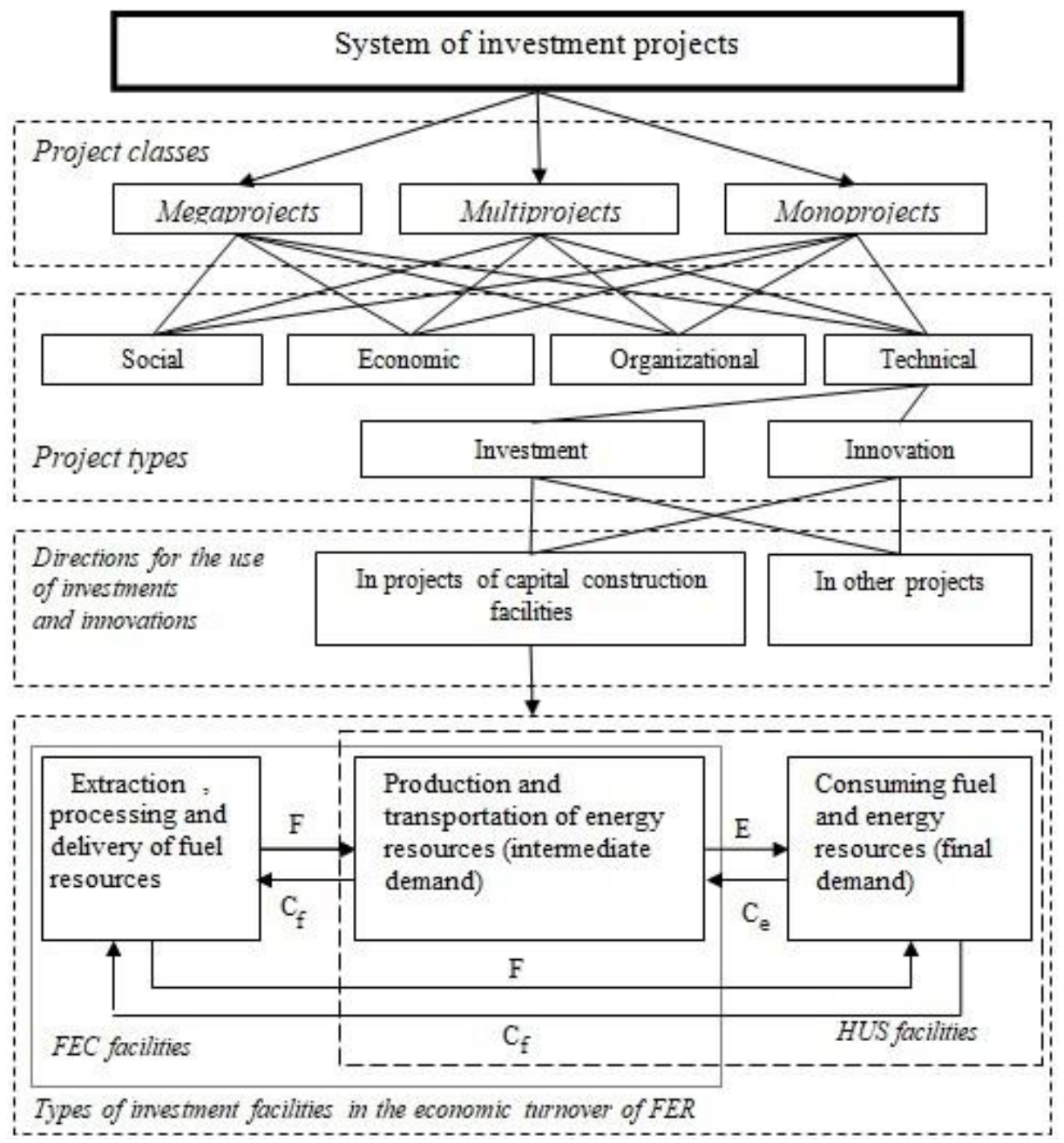

Fig. 1. Hierarchical scheme of the system of investment projects and their interrelation with facilities of investment in economic turnover of FER: $\mathrm{F}$ - fuel; $\mathrm{E}$ - energy (heat, electricity, etc.); $\mathrm{C}_{\mathrm{f}}$ - payment for fuel; $\mathrm{C}_{\mathrm{e}}$ - payment for energy resources.

In terms of income, the maximum receipt of funds should be provided with full satisfaction of the needs determined by the demand for energy resources (Table 1).

Obviously, the constraint (2) leads to the need to ensure the minimum volume of sales of fuel and energy resources in the domestic market. Following condition should be met

$$
\sum_{i=1}^{I} \sum_{j=1}^{J} \sum_{z=1}^{Z} X_{i j=1} \geq A_{i j=1}^{\min }
$$

Table 1. Forecast demand for Russia's energy resources.

\begin{tabular}{|l|l|l|l|}
\hline \multirow{2}{*}{ Indicators } & \multicolumn{3}{c|}{ Years } \\
\cline { 2 - 4 } & \multicolumn{1}{c|}{2010} & \multicolumn{1}{c|}{2015} & \multicolumn{1}{c|}{2020} \\
\hline Domestic demand, mIn. toe, including & $925-1000$ & $940-1055$ & $970-1160$ \\
\hline -gas & $438-464$ & $554-480$ & $446-500$ \\
\hline -liquid fuel & $201-221$ & $200-240$ & $207-275$ \\
\hline -solid fuel & $199-222$ & $208-232$ & $224-256$ \\
\hline -not fuel & $87-93$ & $87-104$ & $93-128$ \\
\hline
\end{tabular}




\begin{tabular}{|l|l|l|l|}
\hline External demand, mIn. toe, including & $580-600$ & $575-610$ & $555-600$ \\
\hline -gas & $322-310$ & $326-306$ & $328-305$ \\
\hline -liquid fuel & $230-260$ & $220-268$ & $200-256$ \\
\hline Total consumption, including storage and reserves, toe & $1515-1610$ & $1530-1670$ & $1540-1790$ \\
\hline
\end{tabular}

Thus, if the fuel producers are interested in reducing the use of fuel and energy resources within the country, a part of the revenues received in addition to sales on the foreign market can be used as investments for the implementation of energy saving measures. Reducing the consumption of FER for the operation of buildings is possible as a result of the introduction of innovative measures and improving the management of the system of characteristics and parameters of buildings and engineering equipment, determined at the stage of their design on the basis of principles of system analysis and effective methods of assessment [8]. The forecast of supply in accordance with the volumes of own production of Russia's energy resources is presented in Table. 2 and shows the lag in the supply of energy resources from demand (Table 1).

Table 2. Forecast of supply of Russia's energy resources.

\begin{tabular}{|l|l|l|l|}
\hline \multirow{2}{*}{\multicolumn{1}{|c|}{ Indicators }} & \multicolumn{3}{c|}{ Years } \\
\cline { 2 - 4 } & \multicolumn{1}{c|}{2010} & \multicolumn{1}{c|}{2015} & \multicolumn{1}{c|}{2020} \\
\hline Own production, mln. toe, including & $1485-1575$ & $1500-1640$ & $1510-1750$ \\
\hline -natural and associated gas, billion $\mathrm{m}^{3}$ & $680-700$ & $690-725$ & $700-750$ \\
\hline -oil and condensate, mln.t & $290-335$ & $280-335$ & $270-350$ \\
\hline -coal and other solid fuels, mln.t & $280-320$ & $300-350$ & $335-400$ \\
\hline -atomic energy, billion kW h & $140-170$ & $150-225$ & $165-330$ \\
\hline -hydropower, billion kW h & $170-177$ & $180-190$ & $190-200$ \\
\hline Renewable energy resources, mln.t. & $3-7$ & $5-12$ & $8-20$ \\
\hline
\end{tabular}

If the production capacity of the producers exceeds the volume of demand, then to compensate for losses from sales at relatively low prices, it may be profitable for the producer to increase production volumes, including for the domestic market. But the increase in production helps to reduce the period of energy security and increase the negative impact on the environmental situation. Therefore, the maximum production volume $(h=1)$ should be constrained by the requirements of ecology $\left(A_{i \mathrm{ecol}}^{\max }\right)$, and the constraint (3) takes the form

$$
\sum_{i=1}^{I} \sum_{j=1}^{J} A_{i j}^{\min } \leq \sum_{i=1}^{I} \sum_{j=1}^{J} X_{i j 1} \leq \sum_{i=1}^{I} A_{i \mathrm{ecol}}^{\max }
$$

Sales on the world market are the most profitable for producers of FER. The volume of sales of FER for export is regulated by international rules in order to regulate world prices, and the constraint for the volume of sales of fuel resources for export is given by condition

$$
\sum_{i=1}^{I} \sum_{j=1}^{J} \sum_{z=1}^{Z} X_{i y z 2} \leq \sum_{i=1}^{I} A_{i j z 2}^{\max }
$$

It should be taken into account that the volumes of export sales are also limited by quotas, and the constraint (5) will be supplemented with the condition

$$
\begin{gathered}
\sum_{i=1}^{I} \sum_{j=1}^{J} A_{i j}^{\min } \leq \sum_{i=1}^{I} A_{i \text { quota }}^{\max } \\
\sum_{i=1}^{I} A_{i \text { quota }}^{\max } \leq \sum_{i=1}^{I} A_{i \text { ecol }}^{\max }
\end{gathered}
$$

The fuel consumption is determined by the amount of required heat and other types of FER that can be generated directly at the consumers' locations where the fuel is delivered or in places remote from direct consumers at distances measured by the length of the main or 
district heat supply networks, which characterizes the degree of centralization of the heat generation source (centralized, autonomous, mixed).

When designing heat and power supply versions for new and reconstructed buildings, it is required to determine such version of the energy generation source (heat, etc.), which will ensure the minimum total costs for its production and delivery when satisfying the needs. A source of investment in energy saving measures can be part of the profit generated by the increase in the sale of FER in the external market due to a reduction in domestic demand or ensuring its growth without changing the amount of extraction of resources. The target function - the minimum of total costs for FER for consumers has the form

$$
F=\sum_{i=1}^{I} \sum_{j=1}^{J} c_{i j} x_{i j} \rightarrow \min
$$

where $x_{i j}$ - the amount of energy resources coming from the $i$-th source to the $j$-th consumer; $c_{i j}$ - the price of a unit of energy resource.

Since the sum of products will have a minimum value only when each factor of all summands is minimal, the conclusion follows that it is necessary to solve the problem of minimizing the amount of heat consumed by the $j$-th facility and the costs of producing and delivering FER to consumers in the complex, which is possible as a result of the development and selection of variants of facilities in the early design stages. To formulate the limitations of the optimization function, it is necessary to determine the normative values for its components.

The economic peculiarity of the process of production and consumption of FER is that the demand of each consumer $\left(b_{j}\right)$ should be satisfied, and the total needs are equal to the total production capacity $\left(a_{i}\right)$. If such a condition is observed in the presence of significant losses of FER, there is an inefficient use of fuel resources, which is paid by the end user, and the task is open. To exclude such a situation in the fuel balance, first of all, it is necessary to invest in energy saving projects aimed at reducing irrational losses of thermal and other energy resources, taking into account economic efficiency. Under the condition (8), the problem is closed

$$
\sum_{i=1}^{n} a_{i}=\sum_{j=1}^{m} b_{i}, \quad i=\overline{1, n}, j=\overline{1, m}
$$

and the constraints have the form:

- needs must be satisfied completely, or in general form

$$
\sum_{i=1}^{n} x_{i j}=b_{j}, \quad j=\overline{1, m}
$$

the volume of generated heat will be delivered to the consumer, or in general form

$$
\sum_{j=1}^{m} x_{i j}=a_{i}, \quad i=\overline{1, n}
$$

- the condition of nonnegativity of variables

$$
x_{i j} \geq 0, \quad i=\overline{1, n}, \quad j=\overline{1, m}
$$

The unit price of a resource is a function of the power of the output source

$$
C_{i j}=f(M) \geq 0
$$

where $C_{i j}$ - the price for the generation and delivery of a unit of energy (for example, heat) from the source to the consumer, depending on the power $(\mathrm{M} \in \mathrm{m})$ of the source of energy generation, depending on the degree of its centralization.

Thus, in order to preserve the resources of the country, it is important to invest in energy saving projects aimed at reducing the consumption of fuel and energy resources in various spheres of economic activity, including the operation of buildings. 


\section{Results}

The proposed simulation model for the design of alternative versions of construction facilities and the choice of rational solutions taking into account environmental, energy and economic efficiency is a combination of actions combined into two blocks and shown in Fig. 2:

Block 1. Choice of the version of space-planning and construction solutions of buildings-consumers of FER;

Block 2. Choice of the heat supply system version according to the power of the heat generation source.

The design versions of the heat supply system are developed using the example of a typical residential microdistrict. The required heat power of the heat supply system to provide heating, ventilation and hot water supply is about $200 \mathrm{MW}$.

Comparable versions of the heat supply system differ in the power of the heat generation sources, in the versions of the schemes of the heat supply system: from fully centralized (version 1) to fully equipped with individual heat generation sources (version 5).

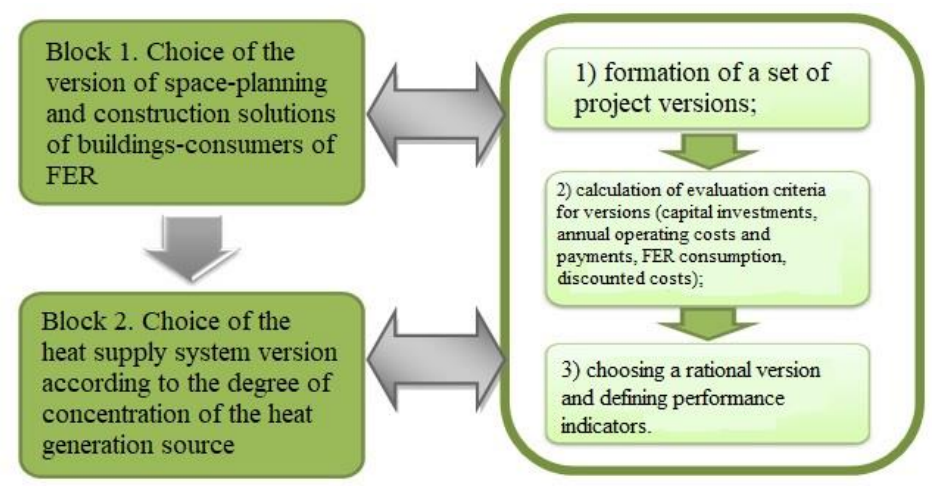

Fig. 2. Simulation model for designing alternative versions and choosing rational solutions taking into account environmental, energy and economic efficiency.

The results of the calculations are given in Table. 3 and show the economic efficiency of the fifth version, which explains the absence of centralized heating networks. However, it should be taken into account that the drawn conclusions are reliable only for specific conditions. And the methodological approach to the predictive assessment of energy consumption in the domestic and foreign markets, taking into account demand, supply and environmental conditions, should be considered universal. And also the economic justification for choosing the power of heat generation sources as a strategic direction for increasing energy efficiency in housing and utility services.

Table 3. Discounted costs and economic effect from the introduction of an economically viable version of the heat supply system.

\begin{tabular}{|l|c|c|c|c|c|}
\hline \multicolumn{1}{|c|}{ Indicators for versions } & 1 & 2 & 3 & 4 & 5 \\
\hline Number of HGS unit / unit power, MW & 1 & 2 & 3 & $84 / 1 \div 6$ & $112 / 1 \div 2$ \\
\hline Capital investments in prices of 2016, mln rub. & 628,1 & 590,8 & 652,3 & 1933,2 & 343,4 \\
\hline $\begin{array}{l}\text { Annual operating costs in prices of 2016, mln } \\
\text { rub. }\end{array}$ & 175,2 & 174,9 & 186,2 & 324,5 & 156,6 \\
\hline
\end{tabular}




\begin{tabular}{|l|c|c|c|c|c|}
\hline $\begin{array}{l}\text { Discounted costs, million rubles, with a service } \\
\text { life of } 25 \text { years, discount rate } e=0.1 \text { and service } \\
\text { life of heating networks } 12 \text { years }\end{array}$ & 2142,7 & 2108,8 & 2263,1 & 4603,1 & $\mathbf{1 6 6 4 , 0}$ \\
\hline $\begin{array}{l}\text { Economic effect of using the fifth version in } \\
\text { comparison with the other versions, million } \\
\text { rubles }\end{array}$ & 478,7 & 444,8 & 599,0 & 2939,0 & 0 \\
\hline Costs of FER (gas, water, electricity), mln.rub. & 127,6 & 129,9 & 132,8 & 247,9 & 137,7 \\
\hline Consumption of fuel (gas), mln cu. m & 47,7 & 48,9 & 50,4 & 159,2 & 62,8 \\
\hline
\end{tabular}

\section{Discussions}

The most problematic area was the heat networks of district heating systems, $47.2-60 \%$ of which were recognized as dilapidated, and 50-70\% reached the end of the established service life. As a consequence - high losses during transportation of coolant and risk of accidents. During underground laying in non-accessible ducts, situations are recorded in a number of areas where the heat networks are constantly flooded with groundwater. The thermal insulation of pipelines with a high coefficient of thermal conductivity does not meet modern requirements. Such operating conditions cause heat loss from 20 to $35 \%$. Some types of boiler equipment have reached the end of their service life, outlived their usefulness, are uneconomical, and do not allow reducing production costs on the basis of resource saving, which increases the cost of a unit of heat, which is constantly increasing.

Taking into account these circumstances, it follows that energy efficient technologies in the housing and utility service, as technologies of the first priority, ensure the independence and sustainability of energy development as the basis for economic growth and energy security of the country.

\section{Conclusion}

The results of a numerical experiment for the implementation of a model for the formation of alternative design versions, using the example of a heat supply system for a residential microdistrict, confirmed the hypothesis of the dependence of performance indicators of projects for providing the population with fuel and energy resources on the degree of centralization of heat generation sources. The economic and energy effects of the choice of an appropriate design version have been determined. It is justified that for the considered conditions, the most preferable version of the microdistrict heat supply system is the version with the installation of individual boiler houses.

\section{References}

1. K. Gumba, S. Belyaeva, IOP Conference Series: Earth and Environmental Science 90(1), 012163 (2017)

2. I. Pan, A. Korre, S. Durucan, Computers \& Chemical Engineering 89, 84-105 (2016)

3. X. Han, H. Wu, Q. Yang, J. Shang, International Journal of Production Economics 182 (2016)

4. I.V. Ilin, O.Yu. Iliashenko, A.I. Levina, Application of service-oriented approach to business process reengineering, Proc. of the 28th IBIMA Conf. - Vision 2020, 768-781 (2016) 
5. O. Kalinina, O. Valebnikova, Advances in Intelligent Systems and Computing, 692, 1315-1322 (2018) DOi - 10.1007/978-3-319-70987-1_139

6. O.A. Kosygina, Techno-economic aspects of the design of buildings. Monograph. Voronezh, 2009.

7. S.A. Mihajlov, V.M. Vasil'ev, V.F. Pomogaev, Energosberezhenie 5, 52-55 (2006)

8. S. Uvarova, O. Kutsygina, E. Smorodina, K. Gumba, E3S Web of Conferences, 33, 03024 (2018) 